\title{
How Proficient is Proficient Enough?: A Look at Proficiency in ESL for Academic Success
}

Marcellino Berardo

\section{Introduction}

We teach English to international students for the purpose of academic achievement at the University of Kansas. The assumption is that students cannot be successful in university classes without the ability to use academic English well. This is most obvious at the lower levels. If the student cannot understand any spoken or written English, then s/he cannot take notes, read textbook chapters, write papers, take exams, or participate in class discussion. This assumption also implies that as the student's English improves, proficiency will become less of a factor in academic success.

This essay is intended to help us discuss assumptions associated with language proficiency and academic success and to identify how well students need to be able to use English in order to fulfill the university's ESL requirement and be successful in their chosen academic program, at least as far as language is concerned. To this end, I begin by characterizing different kinds of proficiency. Then I highlight the literature reviews in this issue, one by Jennifer Hornbaker and one by Parul Sood, that bring up issues related to using proficiency tests as the sole indicators of linguistic readiness for academic success at the university.

\section{Five Characterizations of "Proficient Enough"}

Each university Intensive English Program (IEP) needs an explicit statement to characterize the kind of proficiency in academic English international students need to demonstrate in order to fulfill the university's ESL requirement and study in a particular discipline and/or take General Education courses. The AEC has a highly detailed account of what we mean by "proficient enough" to fulfill the university's ESL requirement. The details are in the goals, objectives, and outcomes for our fifth level class and our Special Studies classes. If students pass these classes with an A or A-, they are considered proficient enough to fulfill the university’s ESL requirement and take General Education courses, which are courses in KU's Core Curriculum. Of course, a score of 160 on our proficiency test is another indication of proficient enough.

Although the AEC has highly detailed accounts of proficiency, we have no short, clear, general statement, guideline, or rule-of-thumb for what we mean by the kind of proficiency our students need to demonstrate in order to be “proficient enough" to fulfill the university's language requirement. Such a general statement would be a practical characterization of proficiency that can guide our instruction and curriculum design, as well as offer our students a summary of what we mean by proficient enough. Below I offer and evaluate five general characterizations of proficient enough in English for academic purposes. All five characterizations are possible but not equally practical or relevant. I consider even the "less desirable" characterizations of proficiency because as our profession changes, these kinds of proficiency may become more relevant to us in the future.

\section{Five Characterizations of 'Proficient Enough':}

Each of the following characterizations of proficiency is intended as a description of one kind of proficiency we can aim for. The AEC is primarily interested in Characterization 1, although elements of other types of proficiency are present in parts of our curriculum, instruction, teacher beliefs, and mission statement.

Characterization 1: English language ability no longer prevents the student from achieving academic success in general education courses, where success is defined as a GPA of roughly 2.0 or higher. 
This kind of proficiency is what the AEC does and should focus on but it is only minimally acceptable. It is acceptable because students will have the English abilities necessary to pass any class at the university, but it is minimal in the sense that students may have to struggle excessively with reading/writing skills, vocabulary, grammar, etc. to pass classes. At this level of proficiency, the student may be academically far above average but his/her language ability may prevent him/her from demonstrating full knowledge of subject matter in courses in KU's Core Curriculum. If a student leaves our program with this kind of proficiency, s/he may struggle with course work in the Core Curriculum but should not fail out of KU or go on probation because of insufficient language ability.

Although minimally acceptable, this characterization of proficiency is the most relevant to our students since most are here to get a degree or study a subject other than English. This characterization is also most practical because it does not require as much instruction as it would take to bring the students to higher levels of proficiency. What the students perhaps lose in language instruction, they gain in the time and the cost it takes to study in the US.

Characterization 2: The student's English is good enough for the student not to struggle "excessively" with class and homework assignments in KU's Core Curriculum.

Putting aside the issue of a precise meaning of "excessively," from the perspective of the AEC this characterization of proficiency may be more acceptable than Characterization 1 because students leave the Center with a linguistic ability to acquire subject matter and demonstrate their knowledge without having to spend an inordinate amount of time and effort on their studies due to English language ability. To achieve this level of academic English, however, it would require higher exit standards than Characterization 1 and correspondingly more instruction. For this reason Characterization 2 is less practical from the students' perspective in the sense that it takes more time, effort, and financial resources to achieve this level of academic English.

Characterization 3: In addition to English proficiency, the student demonstrates non-linguistic abilities such as appropriate study habits, time management skills, and the cultural understanding necessary to navigate the university.

Proficiency Characterization 3 goes beyond language teaching to include non-linguistic strategies for academic success. With the shift of focus from language to general strategies for academic success, we expand our instruction to include tasks that are not evaluated primarily on language ability. Since we are interested in academic success, it is fair to ask how much of our instruction should include tasks that are not primarily evaluated on language ability but do indicate a measure of academic success.

In my view, as language professionals, we should be primarily concerned with the role language plays in academic success and less concerned about the role non-linguistic factors play in academic success. We should focus narrowly on language's role in academia. In particular, we should help our students discover how English-speaking students and scholars use English to discuss and write about, advance, apply, and teach their disciplines. A narrow focus on language is necessary because we are trained in language teaching/learning and not in general university support services. Moreover, our students have limited time and financial resources to acquire enough of the right kind of English to successfully read textbooks, write papers or essays, answer test questions, take notes from lectures, and participate in class discussions.

Characterization 4: The student demonstrates a proficiency that is equivalent to the accepted Internet-based TOEFL scores or IELTS scores. 
For an AEC student to demonstrate a proficiency that is equivalent to the accepted Internet-based TOEFL scores or IELTS scores, we would have to design an in-house test that mirrors the questions, evaluation procedures, and standards of the TOEFL and/or IELTS. ${ }^{1}$ Such an in-house test would be expensive and labor intensive to create. Alternatively, we could ask students to take the actual TOEFL or IELTS after each semester. This would reduce the cost and effort that goes into creating a standardized test and also would reduce the time and effort it takes to grade proficiency tests at the end of the semester.

There is symmetry in having AEC students satisfy the university’s ESL requirement with the same test that incoming students use to fulfill the university's ESL requirement. The symmetry is important because it can represent a single standard for acceptance based on English ability. Another kind of test allows for the appearance of a second standard for those students who did not score high enough on the TOEFL/IELTS before applying to the university.

Any apparent double standard, however, arises out of the inherent nature of university language instruction and corresponding assessment practices. University language instruction does not focus on helping students improve a test score or even on the specific kinds of proficiency that the test score is designed to measure. Language instruction at the AEC, as an example of university language pedagogy, has its own mission. The AEC is “committed to preparing our students linguistically, academically and culturally for university life, providing services to enhance their adjustment and achievement, and advocating for ESL and international students."” Corresponding with our instruction, the AEC proficiency test measures the kind of proficiency that develops out of our instruction. It would be inappropriate to require AEC students to take a test that does not correlate with our instruction.

Characterization 5: The student demonstrates a proficiency that reflects an equivalent to a BA degree in applied English for academic purpose (AEAP).

This kind of proficiency may be more appealing to the language-oriented students, especially those who plan to major in English or teach EFL. Realistically, however, we have few students in our regular program who plan to become English majors or EFL teachers. This makes Characterization 5 most irrelevant to (almost) all of our student body. Although we have few students who would want this level of proficiency, we can still imagine such a degree. Because our profession continues to change, we cannot rule out this possibility for the future. For students who want to become EFL teachers and researchers, a BA degree in Applied English would be a solid launching point for further study in graduate programs in TESL/TEFL.

We can think of a BA in applied English for academic purposes as a blend of Proficiency Characterization 2 and added content courses in applied English linguistics and the discipline of English for academic purposes (EAP). Linguistic courses could center on applied English phonetics and phonology for pronunciation, applied morphology and syntax for grammar/vocabulary, and applied semantics and pragmatics for culture. Students might even take one course in the history of the English language for a historical perspective on the language and a survey English literature course. English literature would provide exposure to the artistic expression of the English language.

\footnotetext{
${ }^{1}$ Currently to satisfy their ESL requirement, new incoming international students at the University of Kansas need scores of 23 or higher on the listening, reading, and writing section of the Internet-based TOEFL and scores of 6.0-6.5 or higher on the relevant sections of the IELTS. Students with lower scores will have to take ESL classes at the AEC.

${ }^{2}$ Our complete mission statement is, “Our students are our highest priority. We are committed to preparing our students linguistically, academically and culturally for university life, providing services to enhance their adjustment and achievement, and advocating for ESL and international students” (http://www.aec.ku.edu/).
} 
EAP as an academic discipline would also include courses on how English is used in academic settings. For an excellent study of academic English as it is used at universities see Biber (2006). For a theoretical perspective on EAP see Bruce (2011). Both books can be found in the AEC library.

\section{Predicting Academic Success from Language Proficiency: Literature Reviews by Hornbaker and Sood}

Determining the point at which language no longer prevents the student from academic success is no easy task. One problem is with the nature of proficiency tests, which are perhaps the most commonly accepted way to place students within an IEP and to determine a student's linguistic readiness for General Education courses. Sood (in this issue) cites the research of Peregoy and Boyle (2005) who "argue that traditional language proficiency tests have limitations that can lead to inappropriate program placement. The limitations on standardized language proficiency tests are (1) the score is based on a single performance; (2) non-linguistic barriers such as unfamiliarity with the test format or procedures may interfere with the testing process; (3) test anxiety; and (4) different standardized language proficiency tests may give different levels for the same student” (p. 11). Sood also cites Stoynoff \& Chapelle (2005) who "point out that the kind of placement tests used in English language programs at various universities do not have the qualities of authenticity and interactiveness that are thought to be the hallmark of communicative language testing” (p. 11).

To make matters more confusing, language ability and academic success may not be linearly related. Hornbaker (in this issue) identifies a "... pattern [in the research] suggest[ing] that there is a range of linguistic skill in which an increase in proficiency increases the chance of academic success. The academic performance of students above that range is not substantially affected by increased proficiency; likewise, the success of students below that range is not improved with increased proficiency until the lower limit of the linguistic threshold is crossed (Vinke \& Jochems, 1993, p. 284). Determining the cutoff points for the proficiency-success connection is a job in and of itself. The task lends direction to future investigations, as the range may vary according to a number of factors, including academic discipline” (p. 27).

Research cited in Sood and Hornbaker suggests that our profession needs to continue to re-examine proficiency tests and the relationship between proficiency and academic success. In particular, there are inherent problems with measuring proficiency and interpreting the score as a predictor of academic success. The literature reviews by Hornbaker and Sood make this point. Their respective reviews of the literature should be considered by university IEPs around the country, including the AEC.

\section{Conclusion}

We operate on the general assumption that students cannot be successful in university classes without proficiency in academic English. At issue is the nature of proficiency in academic English and the relationship between proficiency and success in General Education courses. Each institution should arrive at the most appropriate and relevant way to characterize proficiency in academic English for its international students. I offer and evaluate five general ways to characterize proficiency relevant to the AEC.

Once we get past characterizing proficiency, we need to measure it and use the measurements to predict linguistic readiness for General Education courses. This is, in fact, the primary function of the AEC. Measuring the precise level of proficiency to determine linguistic readiness for undergraduate education is a difficult task. Hornbaker (in this issue) and Sood (in this issue) uncover the difficulty of the task and make an important contribution to understanding this central concern of all university IEPs. 


\section{References}

Biber, D. (2006). University language: A corpus-based study of spoken and written registers. Amsterdam: John Benjamins Publishing Company.

Bruce, I. (2011). Theory and concepts of English for academic purposes. New York: Palgrave MacMillan.

Hornbaker, J. (2013). Language proficiency and academic success. Issues in Language Instruction at the Applied English Center, Special Issue on Proficiency and Academic Success.

Peregoy, S. F. and Boyle, O. F. (2005). Reading, Writing, \& Learning in ESL: A Resource Book for K-12 Teachers. Longman Publishers USA, 88-97.

Sood, P. (2013). Language Proficiency and Assessing Classroom Achievement: A Literature Review. Issues in Language Instruction at the Applied English Center, Special Issue on Proficiency and Academic Success.

Stoynoff, S. \& Chapelle, C. (2005). ESOL tests and testing. Alexandria: Teachers of English to Speakers of Other Languages.

Vinke, A.A., \& Jochems, W. M. G. (1993). English proficiency and academic success in international postgraduate education. Higher Education, 26(3), 275-285. 